\title{
Detection and diagnosis of fault bearing using wavelet packet transform and neural network
}

\author{
Djaballah Said, Meftah Kamel \\ University of Biskra, LGEM Laboratory, Algeria \\ said3988@gmail.com, bttps://orcid.org/0000-0002-8105-9199 \\ meftah.kame@gmail.com, bttp:/ / orcid.org/0000-0002-5671-602X
}

Khelil Khaled

University of Souk. Ahras, Algeria

k_khelil@yahoo.fr

Tedjini Mohsein, Sedira Lakhdar

University of Biskra, LGM Laboratory, Algeria

mohsein.tedjini@gmail.com,

sedira.lakhdar@gmail.com,bttp://orcid.org/0000-0003-1735-2195

\begin{abstract}
Bearings, considered crucial components in rotating machinery, are widely used in the industry. Bearing status monitoring has become an essential step in the deployment of preventive maintenance policy. This work is part of the diagnosis and classification of bearing defects by vibration analysis of signals from defective bearings using time domain and frequency analysis and wavelet packet transformations (Wavelet Packet Transform WPT) with Artificial Neural Networks (ANN). WPT is used for extracting defect indicators to train the neural classifier. The main goal is the determination of the wavelet generating the most representative indicators of the state of the bearings for better detection and classification of defects. Using the WPT-based neural classifier, the obtained simulation results showed that the db6 wavelet with level 3 decomposition is best suited for diagnosing and classifying bearing defects.
\end{abstract}

KEYwORDS. Conditional maintenance; Bearing; The wavelet transform; Neural networks.

\section{OPEN ACCESS}

Citation: Djaballah, S., Meftah, K., Khelil, K. Tedjini, M., Sedira, L., Detection and diagnosis of fault bearing using wavelet packet transform and neural network, Frattura ed Integrità Strutturale, 49 (2019) 291-301.

Received: 16.02 .2019

Accepted: 07.04.2019

Published: 01.07.2019

Copyright: (C) 2019 This is an open access article under the terms of the CC-BY 4.0, which permits unrestricted use, distribution, and reproduction in any medium, provided the original author and source are credited.

\section{INTRODUCTION}

$\mathrm{T}$ he goal of maintenance is to detect failures of rotating machinery before a critical failure occurs. Practically, bearings are one of the most widely used elements in rotating equipment, and its failure is one of the main causes of breakdowns in this type of machines [1]. Therefore, of course, the diagnosis of bearing defects has been the 
subject of several research studies. Most research related to the diagnosis of bearing defects uses vibration signals because they contain valuable information about defects $[2,3]$. In addition, vibration analysis is considered to be the most common and reliable method in this type of analysis [4]. However, ultrasound has also been used appropriately and precisely in the detection of bearing defects [5].

There are different vibration analysis tools to detect and diagnose the appearance of defects in rotating machinery. Many publications synthesize these different methods or tools. They are generally classified into three main categories of vibration data analysis: time analysis, frequency analysis and time-scale analysis. The wavelets transform (TO) be a timescale analysis technique suitable for both stationary and non-stationary signals [6]. The wavelet transform, offering a multiresolution analysis, is very suitable for fault diagnosis [7].

The wavelet packet transform (WPT) is an improvement of the Multi-resolution MRA [8] since it allows decomposition of all frequency sub-bands.

In this work, we focus on the diagnosis of rolling defects, using an intelligent classification system based on Artificial Neural Networks (ANN) and Wavelet Packet Transformation.

The coefficients of the WPT will be used for the extraction of the indicators, in this case, the energy, and the kurtosis, which will drive the network of neurons [9]. Thus, the main objective of our work is the determination of the wavelet generating the most representative indicators of the state of the bearings for better detection and a good diagnosis of the defects.

\section{WAVELET TRANSFORM}

\section{Wavelet packet transform}

7 he wavelet packet method is a generalization of wavelet decomposition that offers a range of possibilities for signal analysis in wavelet analysis; a signal is broken down into approximations and details. The approximation is then itself cut into approximation and second-level detail, and the process is repeated. For decomposition of "n" levels, there are $(n+1)$ possible ways to decompose or encode the signal [10].

In wavelet packet analysis, details, as well as approximations, can be decomposed.

This yields more than $(2 \mathrm{n}+1)$ of different signal decompositions. The wavelet packet decomposition tree is shown in Fig.1. In the case of the detection of bearing defects, this technique makes it possible to obtain the same analysis fineness regardless of the frequencies investigated.

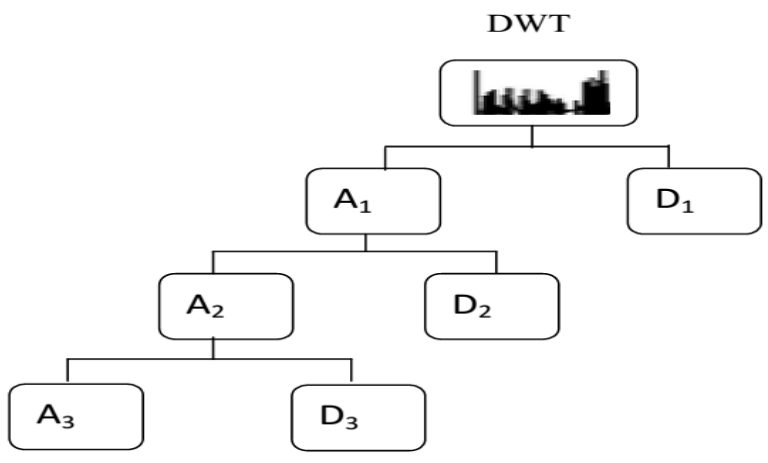

Figure 1: Representation in filter banks of the DWT at $\mathrm{N}=3$ level.

\section{The extraction of indicators}

Due to the complex nature of the machines and the complexity of the associated parameters, it is generally difficult to evaluate the state of a machine directly from the time data. The advent of the wavelet transform has provided an efficient tool for feature extraction of various time signals. As an extension to the discrete wavelet transform, the DWPT, in comparison with the DWT, provides more flexibility in time-frequency decomposition, especially in the high- frequency region. In particular, the DWPT allows the extraction of the indicators (for example, energy or kurtosis) from the frequency sub-bands where the indicators are concentrated[11].

Since the energy content of a signal provides a strong indicator of the signal but is not sensitive enough to incipient defects, kurtosis, on the other hand, is very sensitive to incipient defects but has low stability. Therefore, these two 
indicators, energy, and kurtosis can be combined, instead of using one, to better characterize the vibratory signal and improve fault detection [12].

\section{Bearing DATA CENTER}

$\mathrm{V}$

ibration signals (accelerations) are obtained by exploiting the data made available on the Case Western Reserve University (CWRU, Bearing Data Center) site [13]. The signals are measured at a sampling frequency $\mathrm{Fe}=12$ $\mathrm{kHz}$ for $10 \mathrm{sec}$ on a three-phase $1.5 \mathrm{~kW}$ (2 hp: horsepower) electric machine coupled to a load that determines its speed. The data were acquired from the rolling bearings under different loads (0, 1, 2 and 3 loads) and under different rolling conditions: normal condition, ball defect (BF), inner race defect (IRF), and defect in the outer race (ORF). As illustrated in Fig 2.

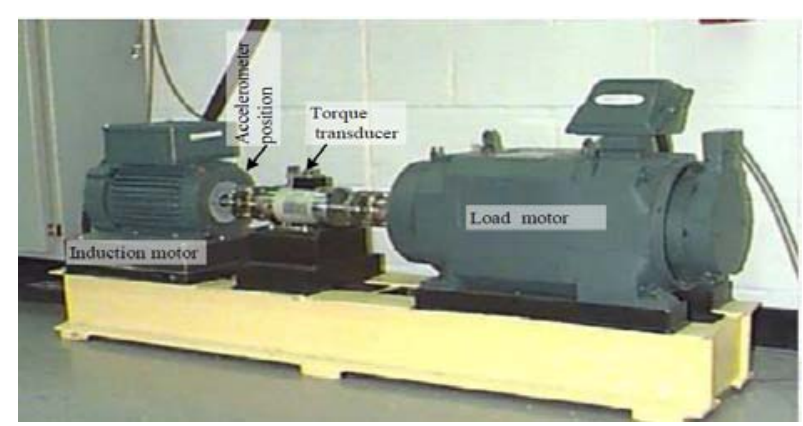

Figure 2: Bearing Test Stand

The bearings used in this work are SKF 6205 type ball bearings. Internal ring, outer ring, and ball defects are introduced into the bearings by Electrical Discharge Machining (EDM). The defect diameters are $0.1778 \mathrm{~mm}(0.007$ inches), $0.3556 \mathrm{~mm}$ $(0.014 \mathrm{in}), 0.5334 \mathrm{~mm}(0.021 \mathrm{in})$ and $0.7112 \mathrm{~mm}(0.028 \mathrm{in})$ corresponding to incipient, moderate, severe and very severe defects respectively.

\section{DIAGNOSIS OF DEFECTS BY METHODS OF ANALYSIS USING A CLASSIFIER ON NEURAL NETWORKS}

\section{Detection of bearing defects by time analysis}

7 or temporal analysis, the input vector of the neural network is formed by the 7 temporal indicators already mentioned and are given by:

$$
\left[\begin{array}{lllllll}
\text { Peak } & \text { RMS } & \text { Ku } & \operatorname{ImF} & \text { CF } & \text { TALAF } & \text { THIKAT }
\end{array}\right]^{T}
$$

Two cases are considered according to the number of outputs. As shown in Fig. 3, we have 4 output neural network and 10 output neural network is shown in Fig. 4.

The performance of the fault diagnosis is evaluated by the recognition rate which is defined as

$$
t_{r \%}=\frac{N_{c}}{N_{t}} \times 100
$$

$N_{c}:$ Number of correct decisions

$N_{t}$ : Total number of tests 
Case_1: 4 output neural network

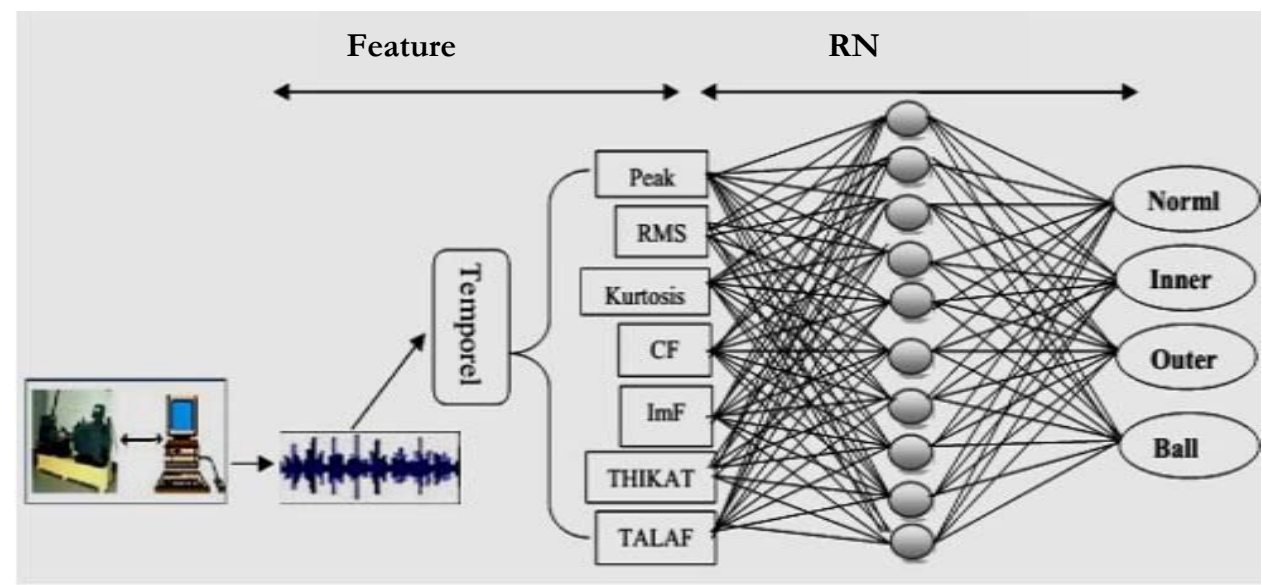

Figure 3: RNA structure $\{7104\}$

Case 2: 10 output neural network

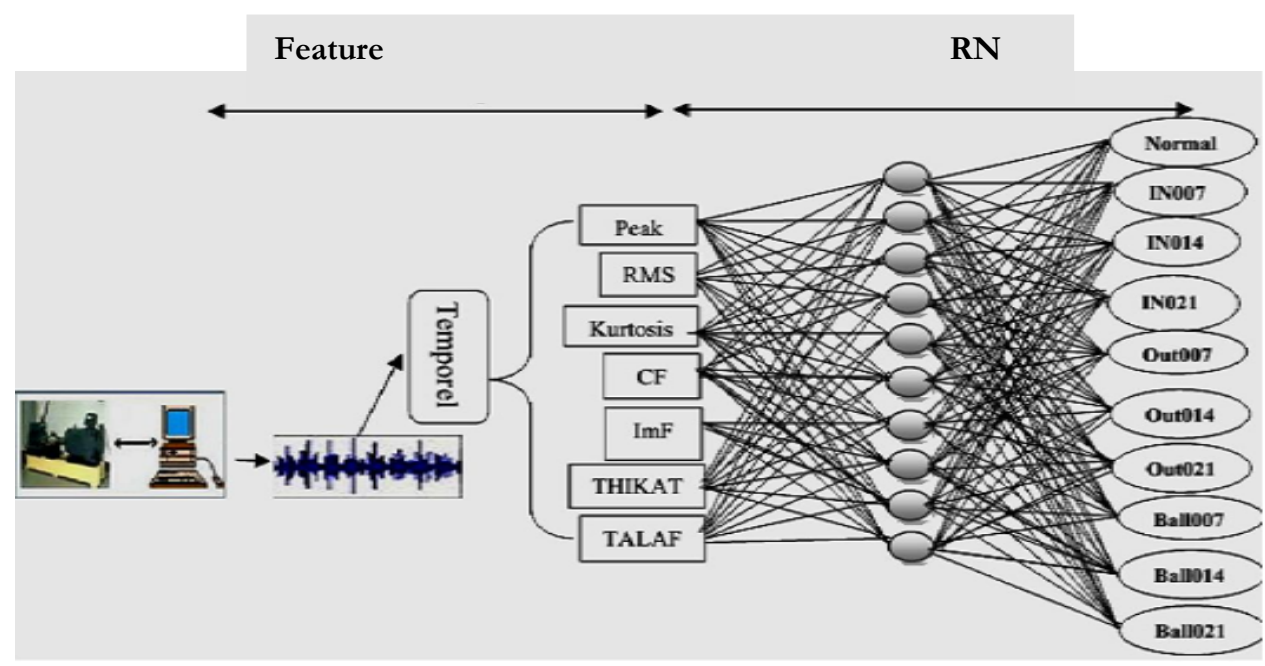

Figure 4: RNA structure $\{71010\}$

Tab. 1 presents the classification performance of the single-layer hidden neural network with 10 neurons using time indicators for the two structures, 4 and 10 outputs:

\begin{tabular}{ccc} 
& Neural network Structure & \\
Number & Number & Performance \\
Of input & Of outputs & Rate $\%$ \\
7 & 4 & 91.10 \\
7 & 10 & 85.34 \\
\hline
\end{tabular}

Table 1: Classification performance of time indicators. 
Diagnosis of defects by time and frequency analysis

Seven time indicators $\left[\begin{array}{lllllll}\text { peak } & R M S & \mathrm{Ku} & \operatorname{ImF} & \mathrm{CF} & \mathrm{TALAF} & \mathrm{THIKAT}\end{array}\right]^{T}$

Three spectral descriptors

$$
\left[x_{\text {fouter }} x_{\text {finner }} x_{\text {fball }}\right]^{T}
$$

Hence, the input vector of the RNA, composed of 10 indicators, is given by

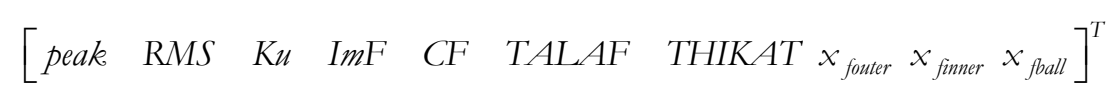

Case 1: 4 output neural network

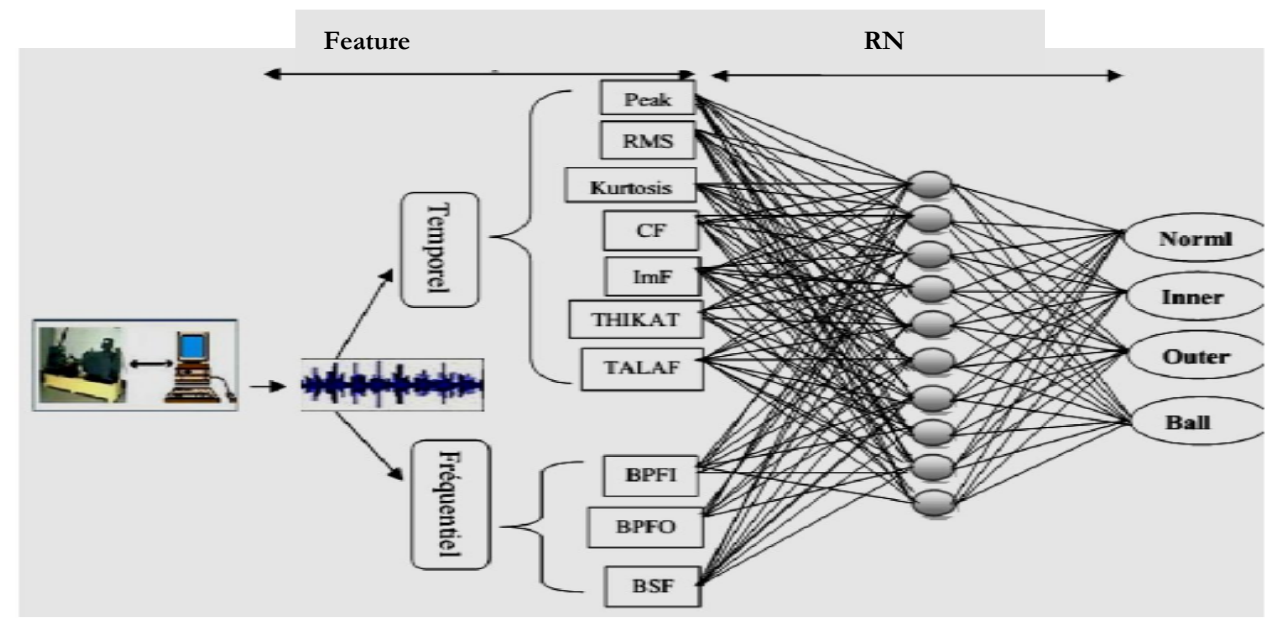

Figure 5: RNA structure $\{10104\}$.

Case 2: 10 output neural network

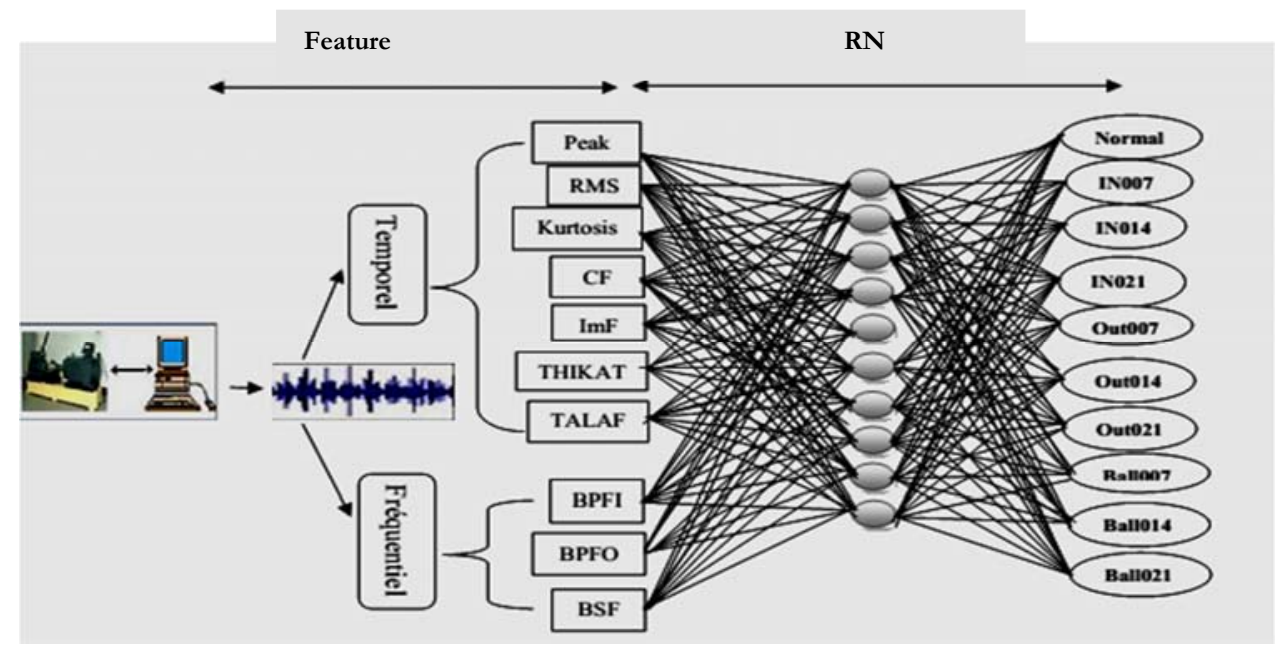

Figure 6: RNA structure $\{101010\}$. 


\begin{tabular}{ccc} 
& Neural network Structure & \\
Number & Number & Performance \\
Of input & Of outputs & Rate \\
10 & 4 & 97.21 \\
10 & 10 & 92.67 \\
\hline
\end{tabular}

Table 2: Classification rate with time and frequency indicators.

From the results shown in Tab. 2, the neuronal classifiers $\{10104\}$ and $\{101010\}$ which is shown in Fig. 5 and Fig. 6 respectively, have classification rates of $97.21 \%$ and $92.67 \%$, respectively. This confirms the contribution of frequency descriptors to the improvement of the classification rate and the diagnosis of defects.

\section{DIAGNOSIS OF DEFECTS BY THE WAVELET TRANSFORM}

\section{Optimal choice of wavelet and decomposition level}

T n practice, unfortunately, there is no wavelet that is better than the others for all cases; it all depends on the intended application. For vibratory analysis based on the wavelet transform, the selection of the mother wavelet depends on its properties or the similarity between the signal and the mother wavelet. Based on the DWPT, this step consists of determining the best mother wavelet (type and order) and the optimal decomposition level best suited to our application. The wavelets chosen for this study are:

- The wavelets of Daubechies: db1, db2, db3, db20, db30, db40 and db44

- Coiflets:

coif1, coif2, ..., coif5

- Symlets:

sym $2, \cdots$, sym 10 and sym 15

For the search of the decomposition level by the wavelet packet transform, we have considered the levels $j=\{3,4,5,6,7\}$. These characteristics can be expressed in a vector such as:

$$
F_{v}=\left[\begin{array}{llllllll}
E_{j}^{1} & E_{j}^{2} & \cdots & E_{j}^{2^{j}} & K_{j}^{1} & K_{j}^{2} & \cdots & K_{j}^{2^{j}}
\end{array}\right]
$$

Fig. 7 shows the classification is based on artificial neural networks.

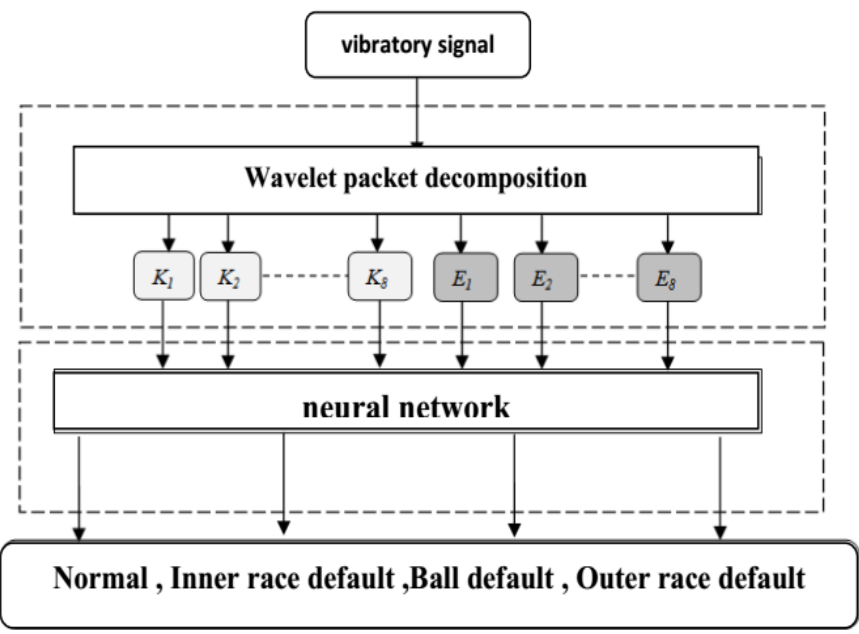

Figure 7: Classification scheme by RNA-based DPWT with a level of decomposition $j=3,4,5,6,7$ 


\section{Configuration Neural network}

The configuration chosen is the following:

- 3-layer network: 1 single hidden layer;

- 10 neurons in the hidden layer;

- $\quad$ Performance error $=10^{-8}$.

We have the database has 180 signals for each rolling condition Among the 720 signals, 60\% and 40\% are exploited for learning the RNA test respectively.

The results showed in Tab. 3, for the three families of wavelets, which the best classification rates are obtained with the classification rate, are obtained with the level 3 of decomposition. In addition, Daubechies wavelets db1, db2, db3, db6, $\mathrm{db} 7$ and $\mathrm{db} 8$ have the best performance in terms of fault classification rates.

Using the wavelets $\mathrm{db} 1, \mathrm{db} 2, \mathrm{db} 3, \mathrm{db} 6, \mathrm{db} 7$ and $\mathrm{db} 8$, with which the best performances are obtained, were performed the neuron classification algorithm 100 times and the results obtained are reported in Tab. 4.

\begin{tabular}{|c|c|c|c|c|c|}
\hline \multirow{2}{*}{ wavelet } & \multicolumn{5}{|c|}{ Level } \\
\hline & 3 & 4 & 5 & 6 & 7 \\
\hline $\mathrm{db} 1$ & 99.21 & 98.17 & 97.91 & 90.88 & 79.68 \\
\hline $\mathrm{db} 2$ & 99.21 & 96.61 & 97.13 & 88.80 & 83.33 \\
\hline $\mathrm{db} 3$ & 99.21 & 97.39 & 98.17 & 89.84 & 86.45 \\
\hline $\mathrm{db} 4$ & 97.91 & 97.39 & 95.83 & 92.70 & 88.80 \\
\hline db5 & 98.17 & 97.13 & 97.39 & 90.88 & 79.94 \\
\hline db6 & 99.21 & 97.91 & 95.57 & 93.48 & 86.19 \\
\hline db7 & 99.21 & 96.87 & 96.61 & 90.62 & 89.58 \\
\hline db8 & 99.21 & 96.61 & 97.39 & 91.66 & 88.80 \\
\hline db9 & 96.87 & 98.17 & 97.39 & 90.36 & 76.04 \\
\hline $\mathrm{db} 10$ & 97.39 & 97.39 & 97.13 & 90.10 & 82.81 \\
\hline db11 & 98.43 & 96.61 & 96.61 & 92.18 & 80.20 \\
\hline db12 & 98.95 & 97.91 & 96.35 & 89.32 & 86.45 \\
\hline db13 & 98.43 & 97.65 & 97.91 & 91.40 & 85.93 \\
\hline db14 & 98.17 & 99.21 & 96.61 & 89.58 & 87.50 \\
\hline db15 & 97.65 & 98.69 & 97.39 & 91.92 & 89.84 \\
\hline db16 & 97.39 & 97.39 & 95.57 & 91.66 & 84.11 \\
\hline db17 & 98.17 & 97.91 & 98.17 & 90.36 & 82.81 \\
\hline $\mathrm{db} 18$ & 96.09 & 97.91 & 97.65 & 89.84 & 90.66 \\
\hline db19 & 98.69 & 97.39 & 97.31 & 92.96 & 75.00 \\
\hline $\mathrm{db} 20$ & 98.17 & 96.35 & 97.65 & 91.40 & 83.66 \\
\hline db30 & 98.17 & 97.39 & 97.65 & 90.88 & 87.50 \\
\hline $\mathrm{db} 40$ & 98.69 & 97.91 & 98.43 & 95.50 & 80.20 \\
\hline $\mathrm{db} 44$ & 98.17 & 98.17 & 97.39 & 96.09 & 85.84 \\
\hline Coif 1 & 98.69 & 97.39 & 94.27 & 89.48 & 79.16 \\
\hline Coif 2 & 98.17 & 97.13 & 97.13 & 91.66 & 84.63 \\
\hline Coif 3 & 97.91 & 97.39 & 95.57 & 86.13 & 85.93 \\
\hline Coif 4 & 98.17 & 96.09 & 94.01 & 85.15 & 82.81 \\
\hline Coif 5 & 99.21 & 96.09 & 93.22 & 86.45 & 75.00 \\
\hline Sym 2 & 98.43 & 97.13 & 97.39 & 89.06 & 76.04 \\
\hline Sym 3 & 97.65 & 98.43 & 97.13 & 93.22 & 85.93 \\
\hline Sym 4 & 98.95 & 98.43 & 97.39 & 90.62 & 87.50 \\
\hline Sym 5 & 98.95 & 98.43 & 97.13 & 92.44 & 89.84 \\
\hline Sym 6 & 98.17 & 97.65 & 95.57 & 90.62 & 83.07 \\
\hline Sym 7 & 98.69 & 96.87 & 95.83 & 89.06 & 80.20 \\
\hline Sym 8 & 98.17 & 96.09 & 96.61 & 91.92 & 84.11 \\
\hline Sym 9 & 98.95 & 98.43 & 96.35 & 92.44 & 80.20 \\
\hline Sym 10 & 98.17 & 96.61 & 94.27 & 82.03 & 75.00 \\
\hline Sym 15 & 98.17 & 97.65 & 97.13 & 93.22 & 76.04 \\
\hline
\end{tabular}

Table 3: Classification rates for different types of wavelet and different levels of decomposition 


\begin{tabular}{ccccccc}
\hline Wavelet & $\mathrm{db} 1$ & $\mathrm{db} 2$ & $\mathrm{db} 3$ & $\mathrm{db} 6$ & $\mathrm{db} 7$ & $\mathrm{db} 8$ \\
Performance \% & 98.95 & 98.95 & 99.21 & $\mathbf{9 9 . 4 7}$ & 98.69 & 99.21 \\
\hline
\end{tabular}

Table 4: Classification rate with decomposition level $\mathrm{N}=3$

We conclude that the optimal wavelet most appropriate to fault diagnosis of bearings is the Daubechies wavelet of order 6 "db6" with a level of decomposition, $\mathrm{N}=3$, has proven its performance in several works dealing with the diagnosis of defects $[14,15,16]$.

\section{Reduction of the vector of indicators}

The application of the wavelet packet transform (DWPT) to the vibratory signal, using the wavelet db6 with decomposition level $\mathrm{N}=3$, generates $2^{3}=8$ frequency sub-bands. Recall that the 16 indicators used in this work are based on energy and kurtosis calculated for each frequency sub-band and are given by:

$$
F_{v}=\left[\begin{array}{llllllll}
E_{3}^{1} & E_{3}^{2} & \cdots & E_{3}^{8} & K_{3}^{1} & K_{3}^{2} & \cdots & K_{3}^{8}
\end{array}\right]
$$

In order to see which of the 16 indicators are sensitive to the state of rotation, the diagrams representing the energies and kurtosis of each sub-band are plotted and shown in Fig. 8 and 9 respectively.

From Fig. 8, we can easily see that the two indicators, in this case, $E_{3}^{5}$ and $E_{3}^{6}$ are almost invariant. For kurtosis, represented by Fig. 9, we can note that the 8 indicators $K_{3}^{1}, K_{3}^{2}, K_{3}^{3}, K_{3}^{4}, K_{3}^{5}, K_{3}^{6}, K_{3}^{7}$, and $K_{3}^{8}$ are sensitive to changing the state of the bearing. As a result, we have maintained the 14 most relevant indicators for the classification of bearing defects that are given by:

$$
F_{v r}=\left[\begin{array}{llllllllll}
E_{3}^{1} & E_{3}^{2} & E_{3}^{3} & E_{3}^{4} & E_{3}^{7} & E_{3}^{8} & K_{3}^{1} & K_{3}^{2} & \cdots & K_{3}^{8}
\end{array}\right]
$$
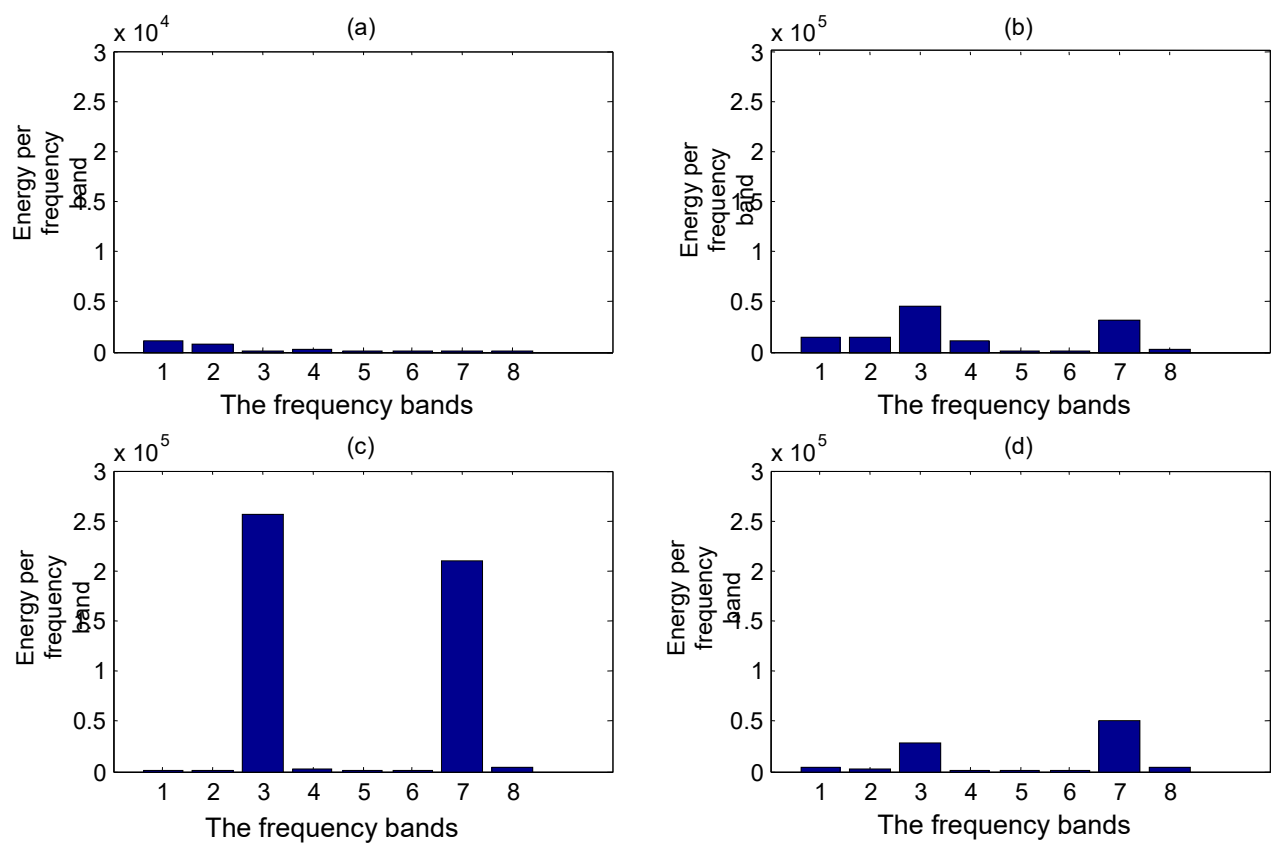

Figure 8: Energy of each sub-band for the four states of the bearing: (a) no fault, (b) defect in the inner race, (c) defect in the outer race, (d) defect in the ball. 


\section{DIAGNOSIS OF DEFECTS BY TRANSFORM WAVELET PACKETS}

7 he diagnosis and classification of bearing defects are performed by an artificial neural network (ANN) whose inputs are energy indicators and kurtosis calculated using coefficients derived from the decomposition level 3 transform wavelet packet ( DWPT) using the db6 wavelet.

We kept the same configuration of the RNA used before. Thus, the structure of the RNA takes the form:

- 3-layer network: 1 single hidden layer;

- 10 neurons in the hidden layer;

- The number of nodes at the input is equal to the number of indicators that is 14 ;

- The number of nodes in the output layer is:

- Case 1: 4 outputs (see Fig. 10) corresponding to the four bearing states.

- Case 2: 10 outputs (see Fig. 11) for detecting the severity of the fault. Corresponding the different defects as well as their diameters:

- Normal.

- Fault in the inner race $(0.007$ and 0.014 and 0.021 inches).

- Fault in the inner race $(0.007$ and 0.014 and 0.021 inches).

- Fault in the ball (0.007 and 0.014 and 0.021 inches).

(a)

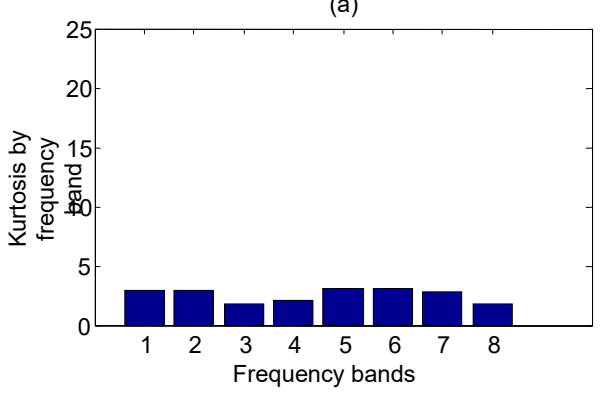

(c)

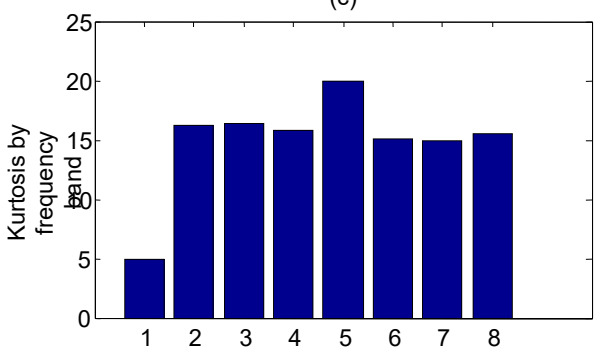

Frequency bands (b)

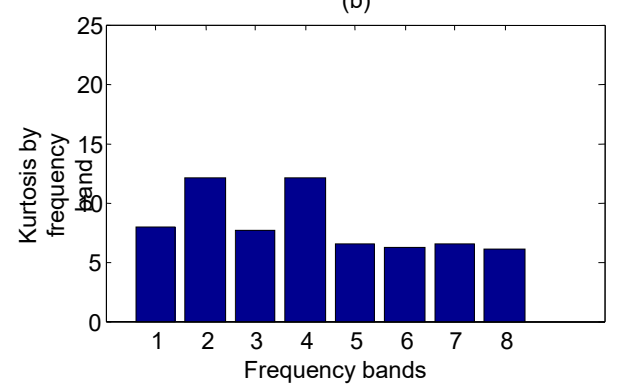

(d)

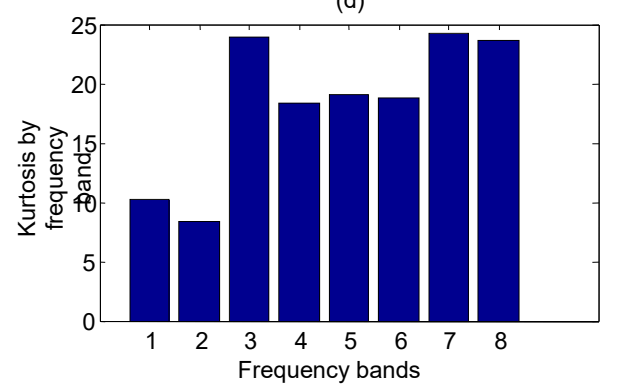

Figure 9: Kurtosis of. each sub-band for the four states of the bearing: (a) no fault, (b) fault in the inner race, (c) fault in the outer race, (d) fault in the ball.

Tab. 5 shows the RNA classification rates based on the wavelet packet transform for both the 4 and 10 output configurations. 


\begin{tabular}{ccc} 
& & \\
& & \\
Number & Number & \\
Of input & Of outputs & Performance \\
& & \\
14 & 4 & 99.47 \\
14 & 10 & 99.33 \\
\hline
\end{tabular}

Table 5: Classification Rate with indicators based on wavelet db6

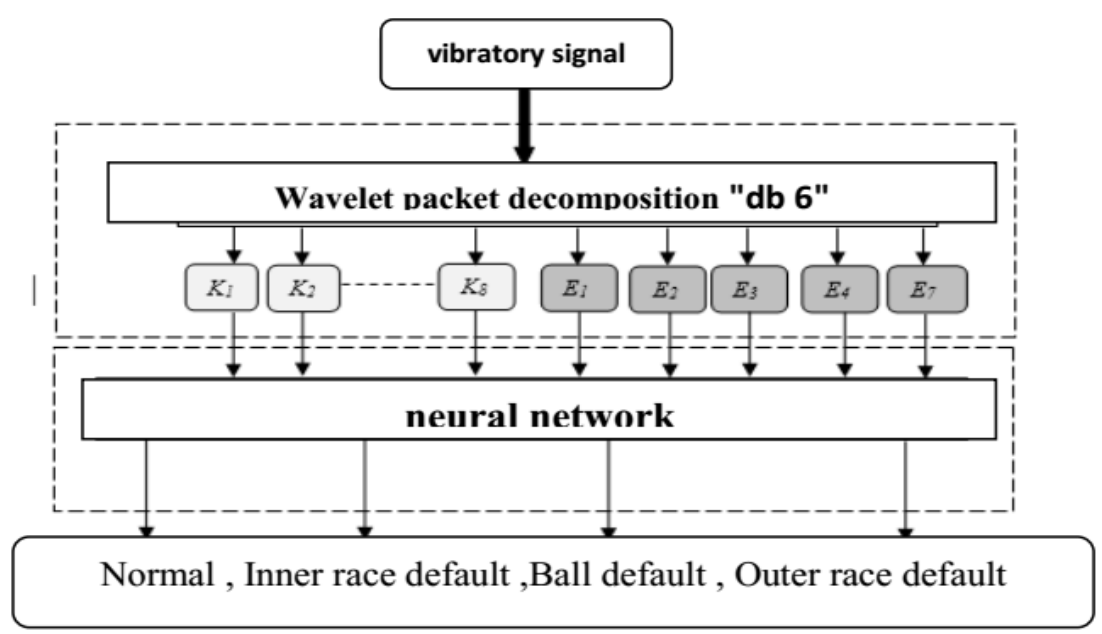

Figure 10: Structure of RNA classifier 4 outputs

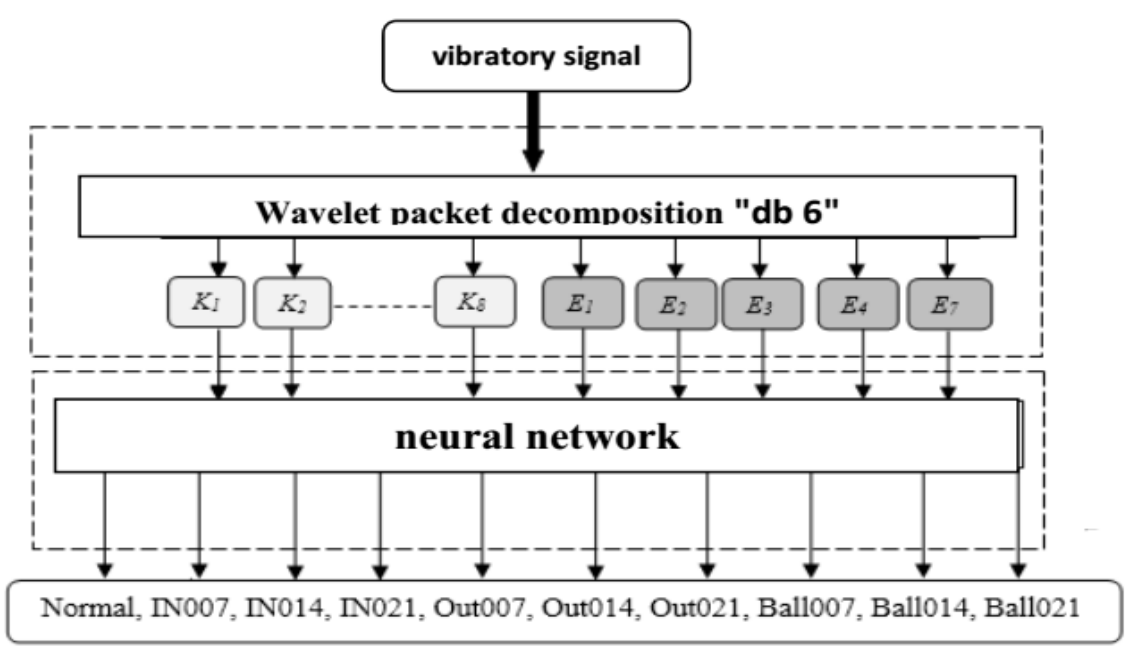

Figure 11: Structure of RNA classifier 10 outputs

The results shown in Tab. 5 show a classification rate of $99.47 \%$ for the detection of the fault location (four outputs), and a rate of $99.33 \%$ for the detection of the diameter (severity) of the fault (ten outputs). These results confirm the efficiency of the use of the wavelet packet transform (with the db6 wavelet) for the extraction of indicators sensitive to the variations of the state of the bearing to be monitored. 


\section{CONCLUSIONS}

$\mathrm{T}$

he work presented in this article is part of the preventive maintenance of rotating equipments and particularly the detection of defects bearings by vibration analysis. The temporal and frequency analysis is used to improve the classification rate and the diagnosis of bearing failure and the time and frequency analysis is used to determining its diameter and location. This objective was mostly achieved with a precision of about $92.67 \%$ when determining the diameter of the defect, and $97.21 \%$ when locating.

Next, we have tried to determine the optimal wavelet best suited to the diagnosis and classification of bearing defects using the wavelet packet transform and Artificial Neural Networks (ANN).

The main objective was to determine the wavelet that generates indicators in this case energy and kurtosis best reflecting the state of the bearings. We could show that the wavelet db6 with decomposition level 3 is the most appropriate diagnosis and classification of bearing fault. This wavelet $\mathrm{db} 6$ and decomposition level 3 improve our result at $99.33 \%$ when determining the diameter of the defect, and $99.47 \%$ when locating

\section{REFERENCES}

[1] Gomez, M., Castejon, C and García-Prada, J. (2014) Incipient Fault Detection in Bearings Through the use of WPT Energy and Neural Networks, Advances in Condtion Monitoring of machinery in Non-Stationary operations, Springer, pp 63-72, DOI: 10.1007/978-3-642-39348-8_4

[2] Du Q., Yang, S. (2007) Application of the EMD method in the vibration analysis of ball bearings, MechSyst Sig Process 21, pp. 2634-2644, DOI: 10.1016/j.ymssp.2007.01.006

[3] Hu, Q., He, Z., Zhang, Z., Zi, Y. (2007) Fault diagnosis of rotating machinery based on improved wavelet package transform and SVMs ensemble, Mech Syst Sig Process 21, pp- 668-705. DOI: 10.1016/j.ymssp.2006.01.007

[4] Aherwar, A., Khalid, Md S., Hemaint, K N. (2012) Vibration analysis of machine fault signature, National

[5] Conference on recent advances in mechanical engineering pp. 487-492

[6] Amarnath, M., Sugumaran, V., Kumar, H. (2013) Exploiting sound signals for fault diagnosis of bearings using decision tree, Measurement. 2013 Apr; 46(3), pp. 1250-1256, DOI: 10.1016/j.measurement.2012.11.011

[7] Rosani M. (1999). Signal analysis in transient applying the wavelet technique, [Master Thesis], Sao.Paulo University

[8] Memon, A., Khokhar, S., Memon, Z. (2014). Discrete Wavelet Transform and Multiresolution Analysis Algorithm with Appropriate Feedforward Neural Network Classifier For Power System Transient Disturbances, Sci.Int.(Lahore), 26(5), pp. 2231-2238.

[9] Liu, B., Ling, S. (1997) Machinery diagnostic based on wavelet packets, Vib Control 3, pp. 5-17. DOI: $10.1177 / 107754639700300102$.

[10] Kafiey Khan, A., Azizur, R. (2010) Wavelet Based Diagnosis and Protection of Electric Motors, Fault Detection, Wei Zhang (Ed.), InTech, DOI: 10.5772/9068.

[11] Michel, Misiti., Yves, Misiti. (2003). Les ondelettes et leurs applications, Edition Hermes, Paris.

[12] Altmann, J., Mathew, J. (2001). Multiple band pass autoregressive demodulation for rolling element bearing fault diagnosis, Mech Syst Signal Process, 15, pp. 963-977, DOI: 10.1006/mssp.2001.1410.

[13] Pandya, D_H., Upadhyay, S_H., Harsha, S P. (2013) Fault diagnosis of rolling element bearing by using multinomial logistic regression and wavelet packet transform, DOI: 10.1007/s00500-013-1055-1.

[14] Loparo, K. (2018). Bearings Vibration Data Set, Case Western Reserve University. Available online: http://csegroups.case.edu/bearingdatacenter/home (10 January 2018).

[15] Castejon, C., Lara, O., García-Prada, J. (2010) Automated diagnosis of rolling bearings using MRA and neural networks , Mech Syst Sig Process 24, pp. 289-299, DOI: 10.1016/j.ymssp.2009.06.004.

[16] Lara, O., Castejon, C., Garcia-Prada, J. (2006) Bearing fault diagnosis based on neural network classification and wavelet transform, WSEAS Trans. DOI: 10.5555/1974867.

[17] Adewusi, S.A. (2001) Wavelet analysis of vibration signals of an overhang rotor with a propagating transverse crack, J Sound Vib 5, pp. 777-793, DOI: 10.1006/jsvi.2000.3611. 